\title{
ENTSAGUNG ODER DESILLUSION? DER STUDENT ALS PARADIGMA DES SPÄTREALISMUS IN DER TSCHECHISCHEN UND DEUTSCHEN LITERATUR ${ }^{1}$
}

\author{
ALŽBĚTA PEŠTOVÁ
}

\section{ABSTRACT \\ RENUNCIATION OR DISILLUSION? THE STUDENT AS A PARADIGM OF THE LATE REALISM IN THE CZECH AND GERMAN LITERATURE}

The progressive industrialization and its economic consequences led to a decline of the traditional bourgeois values, and to the rise of the modern metropolitan society, in the second half of the 19th century, where the individual was focused mainly on career ambitions. The literature of late realism and early modernism takes up this process and presents increasingly disillusioned literary characters who fail due to the difference between their social and political ideals, and reality. The phenomenon of disillusion can be found both in Czech as well as in German Moravian literature. The study analyses and compares the student novels Santa Lucia by the Czech naturalist Vilém Mrštík and Die Vaclavbude by the German Moravian author Karl Hans Strobl (and briefly the novel Výpravy chudých by Antonín Sova) with regard to the patriotic ideals, the disillusioning processes, the images of German and Czech ethnicity, as well as the image of the metropolis Prague as they are depicted in the novels.

Key words: late realism, naturalism, student, Vilém Mrštík, Karl Hans Strobl, Antonín Sova

\section{ABSTRAKT ODŘÍKÁNÍ NEBO DEZILUZE? STUDENT JAKO PARADIGMA POZDNÍHO REALISMU V ČESKÉ A NĚMECKÉ LITERATUŘE}

Postupná industrializace a její ekonomické důsledky vedly k poklesu tradičních buržoazních hodnot a vzestupu moderní velkoměstské společnosti v druhé polovině 19 . století, kdy se jedinec zaměřoval především na profesní ambice. Literatura pozdního realismu a raného modernismu ztvárňuje tento proces a představuje literární postavy podléhající deziluzi a selhávající kvůli rozdílu mezi jejich společenskými a politickými ideály a skutečností. Fenomén deziluze lze nalézt jak v české, tak i německé

1 Der Beitrag wurde gefördert vom Projekt der Palacky-Universität in Olmütz IGA_FF_2015_038 Kategorie regionality v kulturních vědách. Německá literatura v Českých zemích jako paradigma (Die Kategorie der Regionalität in den Kulturwissenschaften. Die deutsche Literatur in den Böhmischen Ländern als Paradigma). 
moravské literatuře. Studie analyzuje a porovnává studentské romány Santa Lucia českého naturalisty Viléma Mrštíka a Die Vaclavbude německého moravského autora Karla Hanse Strobla (a krátce se dotýká románu Antonína Sovy Výpravy chudých) s ohledem na vlastenecké ideály, proces deziluze, literární obrazy německé a české národnosti, stejně jako obraz metropole Praha ve jmenovaných románech.

Klíčová slova: pozdní realismus, naturalismus, student, Vilém Mrštík, Karl Hans Strobl, Antonín Sova

Die geistigen und wissenschaftlichen Entwicklungen im Laufe der zweiten Hälfte des 19. Jahrhunderts, in der sich das Welt- und Menschbild grundsätzlich veränderte, zeichnen das Ende der literarischen Epoche des bürgerlichen Realismus vor. Der „Glaube an die Realisierbarkeit eines bürgerlich-humanen Wertesystems" (Becker 2003: 267), der in dem realistischen Verklärungsprinzip zum Ausdruck kommt, macht der Erkenntnis der modernen, kalkül- und gewinnorientierten Gesellschaft Platz. Bei Moritz Baßler ist der Übergang zwischen dem Spätrealismus und der frühen Moderne durch die Begriffe „Entsagung und Routine“ (Baßler 2013: 3-24) geprägt. Unter Entsagung ist der Verzicht auf individuelle Bedürfnisse und die Konzentration auf das ,große Ganze' gemeint, die die Figuren des poetischen Realismus auszeichnet. Die realistischen Texte vermitteln somit immer das Bild einer „idealen Wirklichkeit“ (Becker 2003: 120), das einen überwölbenden „Metacode“ (Baßler 2013: 8) - beispielweise ,Aufrechterhaltung der Moral', ,Bildung', Nation' oder einfach ,Glück' - aufweist. Die Vermittlung wird, typisch für realistische Schreibweisen, durch „keinerlei störende Textverfahren [...] zwischen Lesen und Verstehen" (Baßler 2013: 3) erschwert, d. h. dass der Übergang zwischen der Textebene und der Darstellungsebene, so Baßler, automatisiert verläuft. Dies sei bei der Literatur der frühen Moderne nicht mehr der Fall. Sie gibt die realistische Forderung der „poetischen Diegese auf ein wesentliches Ganzes zu verweisen“, auf und verfährt stattdessen bei der Textproduktion "nach willkürlich gesetzten Spielregeln“ (Baßler 2013: 14), die von den allgemein gültigen oder allgemeine Gültigkeit beanspruchenden Figurengestaltung und Handlungsaufbau auf unterschiedliche und eigenartige Weise abweichen. Diese Textproduktionsart versteht Baßler als eine "erzählerische Routine“ (Baßler 2013: 14), die den gemeinsamen Nenner der vielen literarischen Bewegungen der Jahrhundertwende darstellt und den Übergang des Spätrealismus in die frühe Moderne lesbarer macht. Anhand der Erkenntnis, dass die realistische Programmatik mit der fortschreitenden Industrialisierung und Kapitalisierung der Welt nicht mehr aufrechtzuerhalten ist, konstatiert Sabina Becker bei spätrealistischen Texten das Schwinden linearer Bildungsgeschichten, anstelle derer als Folgen der "Veräußerlichung und Entleerung der ehemaligen Werte“ und „der Ökonomisierung des Lebens" (Becker 2003: 230) desillusionistische Erzählungen treten. Als Beispiel dieser Endphase nennt sie Wilhelm Raabes Roman Die Akten des Vogelsangs (1896), in dem das realistische Konzept bürgerlicher Wertegemeinschaft nicht mehr funktioniert. Noch härter erscheint dieser Verfall in dem bereits zehn Jahre früher erschienenen Roman Martin Salander (1886) von Gottfried Keller, in dem die illusionsraubende Kluft zwischen den ethischen Ansprüchen und der Realität so groß wird, dass 
Keller selbst, so Becker, keine Möglichkeit zu einem sinnvollen Ende des Textes sah und ihn lieber ins Fragmentarische auslaufen ließ (vgl. Becker 2003: 267). Der Roman wurde „als ,Abschiedsbuch [...] eines desillusionierten Repräsentanten des Bürgerlichen Realismus [gelesen], der erkennt und längst zugibt, dass die Zeit über die ehemaligen Ideale und Werte hinweggegangen ist." (Becker 2003: 267) Desillusionismus ist in der deutschen Literatur zu dieser Zeit also offenbar ein weit verbreitetes Phänomen. Als Begriff kommt er allerdings in der deutschen Literaturgeschichte meist nur als Adjektiv vor und bildet nach aktueller Übersicht keinen selbstständigen Posten in einschlägigen Lexika. In der tschechischen Literaturwissenschaft wird der Begriff dagegen als kulturspezifisches Kriterium tschechischer Texte angewandt, die unter dem Einfluss des französischen Naturalismus Zolas und Balzacs sowie des Russen Dostojewski am Ende des 19. Jahrhunderts entstanden (vgl. Hodrová 1989: 127-138). Als Paradebeispiel des tschechischen desillusionistischen Romans wird dabei das Werk Santa Lucia (1893) von Vilém Mrštík (1863-1912) angeführt (vgl. Hobland 1991: 50-63), das hier näher betrachtet werden soll. Auch in der deutschböhmischen und -mährischen Literatur häufen sich um 1900 Texte, die den Illusionsverlust thematisieren. Für beide Literaturen ist dabei kennzeichnend, dass es sich häufig um Lebensläufe von Studenten handelt.

Der Ausgangspunkt der hier ausgeführten Überlegungen sind die Romane Die Vaclavbude (1902) des Deutschmährers Karl Hans Strobl (1877-1946) und der bereits genannte Text Santa Lucia des tschechischen Naturalisten Mrštík. Bei beiden Texten handelt es sich um Studentenromane, ${ }^{2}$ die innerhalb der Verbindung der Darstellungsebene mit der Raumgestaltung dem Genre innovative Impulse geben konnten. Zudem entstanden beide Texte um die Jahrhundertwende und machen das zeitgenössiche Prag zum Schauplatz der Handlung. Erzählte Zeit sowie Ort der Handlung dokumentieren dementsprechend die gesellschaftspolitischen Spannungen zwischen der deutschsprachigen und tschechischen Bevölkerung in Prag, indem damals vorherrschende stereotype Vorurteile vermittels Literatur den Lesenden zugänglich gemacht werden. Die beiden Texte vermitteln zwei unterschiedliche Bilder des studentischen Lebens und der damit verbundenen Konzepten von ,Nation' der jeweiligen Protagonisten, weisen jedoch auch interessante Gemeinsamkeiten auf.

\section{Vilém Mrštík: Santa Lucia (1893)}

Der aus Mähren stammende Schriftsteller Vilém Mrštík nimmt im tschechischen literarischen Feld eine etwas problematische Position ein. Von der Kritik wurde er zwar für seine naturalistischen, in innovativ bildhaftem Stil geschriebenen Texte zunächst gefeiert, später warf man ihm aber eine mangelhafte Anpassung an die „moderne“ Strömung des Symbolismus und eine zu geringe Verwendung psychologischer Elemente vor (vgl. Pytlík 1989: 151-152 und 11-15). Erschöpft von den polemischen Attacken seitens der Literaturkritik, namentlich vertreten durch die jüngere Schriftsteller- und Kritikergeneration

Der Studentenroman erfreute sich in der deutschen Literatur ab Hälfte des 19. Jahrhunderts großer Beliebtheit, wobei mehr das studentische Leben und seine burschenschaftliche Ausprägung in Vordergrund standen als politische Intentionen. Zu genauer Definition des Studentenromans vgl. Wieser (1994: V) und Weierhausen (2004: 61f.). 
wie F. X. Šalda (1867-1937), zog sich Mrštík nach Diváky (Diwak) in Südmahren zurück, wo er einerseits an materieller Not, andererseits am Desinteresse des Literaturbetriebs litt. Am 2. März 1912 beging er schließlich Selbstmord.

Der Roman Santa Lucia, der sowohl autobiographische Einblicke gewährt, als auch das tragische Schicksal des Literaturkritikers und Freundes von Mrštík, Hubert Gordon Schauer schildert (vgl. Pytlík 1989: 155-210), weist einen starken Einfluss v. a. des französischen Naturalismus auf, dessen eindringlicher Verfechter innerhalb der tschechischer Literatur Mrštík war. Der Veröffentlichung gingen dementsprechend mehrere theoretische Arbeiten zum Naturalismus Zolas (vgl. Pytlík 1989: 52f.) voraus, der Roman selbst wurde zum Wegbereiter einer Reihe weiterer tschechischer Texte. ${ }^{3}$ Der Aufbau des Textes entspricht dem narrativen Modell, das Mrštík anhand französischer Erzähltexte entwickelte. ${ }^{4}$ Er modifiziert allerdings, wie Hodrová detailliert nachgewiesen hat, einige der typischen Merkmale dieses Typus, die dadurch der Vorstellung Prags als Ort vaterländischer und erotischer Illusionen (vgl. Hodrová 1989: 128) gerecht werden sollen.

Die Exposition des Romans Santa Lucia spielt im kleinstädtischen Milieu eines Armenviertels von Brünn, der mährischen Heimat des Protagonisten Jiří Jordán. Jordán wird bereits hier als Außenseiter geschildert, der unter der steif bürokratischen und verknöcherten Erziehung des österreichischen Gymnasiums leidet. Aus der Perspektive Jordáns laufen in der Hauptstadt Prag alle Ideale der tschechischen Nationalbewegung zusammen. Wie keine andere Stadt verkörpert ihm Prag gleichzeitig die Gedanken von Humanität. Im Unterschied zu seinen französischen Vorbildern (Zola, Stendhal, Balzac) strebt er nicht nach gesellschaftlichem Aufstieg und materiellem Gewinn, sondern will am ideellen und kulturellen Leben der Tschechen in der Hauptstadt teilnehmen. Bei der Ankunft in der Großstadt trifft der Protagonist auf den Medizinstudenten Hégr. Dieser weiht ihn in die gesellschaftlichen Verhältnisse der Großstadt ein und erfüllt somit die Rolle eines in der Großstadt bereits integrierten Initiators, der für das Genre des desillusionistischen Romans typisch ist (Hodrová 1989: 131). In seinen pragmatischen Ansichten nimmt er die spätere unausweichliche Desillusionierung Jordáns vorweg. Die Handlungsorte, zwischen denen sich der Protagonist bewegt, sind größtenteils auf die Prager Straßen, Kneipen und die Wohnung des Protagonisten begrenzt, die ihm durch ihre erhöhte Lage im Stadtteil Königliche Weinberge (Vinohrady) stundenlange Beobachtungen der Verwandlungen Prags bei unterschiedlichen Tageszeiten gewährt, zugleich aber auch die bis zum Ende bestehende Isolierung Jordáns vorwegnimmt. Jordáns Hoffnungen an das neue Leben in Prag werden im weiteren Verlauf der Handlung nach und nach enttäuscht. Er schreibt sich zwar als Student an der Universität ein, besucht aber fast nie den Unterricht. Trotz all seiner Versuche bleibt er arbeitslos, findet keinen persönlichen

Beispielsweise die Romane Nejzápadnějǔš Slovan (Der westlichste Slawe, 1893) von Karel Matěj Čapek Chod (1860-1927), Gotická duše (Die gotische Seele, 1900) von Jiří Karásek ze Lvovic (1871-1951) oder Ivi̊v román (Ivos Roman, 1902) von Antonín Sova (1864-1928). Vgl. Hodrová (1989: 128).

4 Wie der Protagonist Mrštíks streben auch die Hauptfiguren der französischen Romane der Desillusion einen persönlichen Erfolg an, den sie sich in der Welt der Großstadt erhoffen. Eine Integration in die großstädtische Gesellschaft gelingt ihnen jedoch in der Regel nicht. Die unerfahrenen Protagonisten stehen meist zwischen einer ihnen freundschaftlich verbundenen Initiationsfigur und einer oder mehreren unzuverlässigen weiblichen Akteurinnen. Auch dieses triadische Figurenschema übernimmt Mrštík aus der französischen Literatur. Für diese und weitere strukturelle Åhnlichkeiten mit dem französischen Desillusionierungsroman vgl. Hodrová (1989: 129-132). 
Anschluss und auch seine Liebesaffären laufen ins Leere. Von den vermeintlichen Familienfreunden, die alle dem wohlhabenden Bürgertum angehören, werden ihm zunächst Versprechungen gemacht, die sich später jedoch als falsch erweisen. Infolge seiner elenden Lebensumstände erkrankt er schließlich an Tuberkulose und stirbt einsam, „jako by tam nebyl nikdy ani patřil" [als ob er dorthin [in die Stadt] nie hineingehörte"] (Mrštík 1948: 347), in einem Armenkrankenhaus.

Die Illusionen Jordáns sind wie bereits erwähnt zweierlei Art - er hofft in Prag die Gesellschaft von ,echten', d. h. sittlichen und starken Tschechen zu finden und sehnt sich gleichzeitig nach erotischen Erlebnissen. Durch die geistige Enge des kleinstädtischen Milieus (als welches hier die um 1890 durchaus industrialisierte und schnell wachsende Stadt Brünn überraschend stilisiert wird), durch eine verknöcherte Erziehung sowie durch materielle Not ist Jordán für die idealisierende Sehnsucht nach der tschechischen Großstadt geradezu determiniert. Seine natürliche Intelligenz wehrt sich gegen konventionelle Formen, seine humanistischen Überzeugungen in Bezug auf zwischenmenschliche Liebe und Respekt kollidieren mit seiner provinziellen Umgebung und machen ihn zum Außenseiter. Vom Umzug in die Stadt verspricht sich Jordán eine radikale Veränderung dieses Zustands, eine Befreiung „Z těch železných rukou okolností, které jej nutily k životu naprosto jinému, než k jakému jej sváděla živá jeho obraznost [aus den eisernen Händen der Umstände, die ihn zu einem Leben zwangen, das völlig unterschiedlich von dem Leben war, zu welchem ihn seine lebhafte Phantasie verführte] (Mrštík 1948: 96). In der Gesellschaft Prags glaubt er dabei eine Art neue Menschheit zu finden, die sich durch eine überragende Moral auszeichnet:

A byla to Praha, ta poetická, stověžatá Praha se skalnatými srázy, vysokými břehy teras, od které si sliboval vysvobození z dusného toho karceru svých nejkrásnějších dnů. V jejích černých konturách vybájil si zcela jiný, čistě ideální svět [...]. V ní viděl lidi, jakých snad posud nikdo na světě nepoznal [...] dobrý, mravný vrchol všeho, co duše jeho bájila pode jménem lidskost.

[Und es war Prag, das poetische, hunderttürmige Prag mit seinen felsigen Hängen und hohen Terrassenufern. Von ihm versprach er [Jordán] sich die Befreiung aus dem stickigen Karzer seiner schönsten Tage. In seinen schwarzen Konturen erfand er eine vollkommen andere, rein ideale Welt [...]. Er sah darin Menschen, die die Welt bisher wohl noch nie erblickte $[. .$.$] den guten, sittlichen Höhepunkt von Allem, was seine Seele unter dem Namen$ Menschlichkeit verstand.] (Mrštík 1948: 36)

Die Sehnsucht Jordáns wird keinesfalls als Einzelerscheinung, sondern als Massenphänomen geschildert, das die ganze mährische Provinz sowie alle Altersgenerationen prägt. Die geradezu magische Ausstrahlung Prags als Mittelpunkt des Tschechentums ist dabei nicht durch zeitgenössische Kämpfe gegen die Deutschen, sondern durch Bilder aus tschechischen Sagen und Mythen über die Gründung der tschechischen Nation bestimmt:

Nikdo tu černou krasavici nemiluje tak jako ten holý skoro ještě dorost našich niv a pahorků. S hlavou plnou pověstí o mythických postavách dějin touží po seznání těch míst, kde vznikly ty pověsti, kde jsou domovem ty pohádky o Kazi, Tetě, Libuši, Kroku [...] holohlaví a nemožní už starci [...] vnuky své učili písni starodávné a smutné: Ještě jednou, dřív než 
umřu, Prahu chtěl bych viděti ${ }^{*}$ děti poslouchaly, o Praze snily, s Prahou uléhaly k spánku, s Prahou vstávaly ráno [...]. Praha tak rostla živá v jejich paměti, krásná v rudé záři hořícího krbu, svůdná v žhavých barvách nadsmyslných iluzí.

[Niemand liebt die schwarze Schönheit so sehr wie das fast noch bartlose Jungvolk unserer Auen und Hügel. Mit Kopf voll von Sagen über die mythischen Gestalten der Geschichte sehnen sie sich, die Orte kennenzulernen, wo diese Sagen entstanden, wo die Märchen über Kazi, Teta, Libuše, Krok zu Hause sind [...] kahlköpfige Greise [...] brachten ihren Enkelkindern das alte und traurige Lied bei: ,Noch einmal, bevor ich sterbe, möchte ich Prag sehen - die Kinder hörten zu, träumten von Prag, mit Prag legten sie sich zum Schlaf, mit Prag standen sie morgens auf [...] Prag war lebendig in ihrem Gedächtnis, war wunderschön in dem roten Licht des Kamins, verführerisch in den glühenden Farben übersinnlicher Illusionen.] (Mrštík 1948: 40-42)

Die Stadt wird neben diesen vaterländischen Konnotationen im Laufe der Handlung immer wieder als Figur einer Geliebten stilisiert, die das Liebesobjekt des Protagonisten darstellt und derer Bilder seinen inneren Zustand widerspiegeln. Mit dem fortschreitenden Desillusionierungsprozess Jordáns ändert sich die Stadt dementsprechend von einer „svůdnice černá“ [schwarzen Verführerin] (Mrštík 1948: 39) zu einer käuflichen Hure, die sich für ihre Schönheit rächt und zudem Jordán „auf jedem Schritt und Tritt ermorden will“" [Praha [...] vraždila ho nyní na každém kroku.] (Mrštík 1948: 320) und damit die sittliche Verdorbenheit der Stadt symbolisiert. Der moralische Verfall wird im Text mit dem Weiblichen und Animalischen konnotiert. Mrštík hält sich an den für die impressionistische Malerei typischen Grundsatz „krajina jako výraz duše, dojmu a pocitu“ [der Landschaft als eines Ausdrucks der Seele, der Impression und des Gefühls] (Pytlík 1989: 125).

Die oben angedeuteten Erwartungen Jordáns kontrastieren scharf mit den späteren krassen Bildern der unmoralischen tschechischen Gesellschaft Prags, die sein Scheitern verursacht. Abgebildet werden v. a. niedrigere Gesellschaftsschichten, denn dem Milieu entsprechend, in welchem sich die Handlung abspielt, bleiben bürgerliche und höhere Gesellschaftskreise dem Protagonisten verschlossen. Der Text ist also in dieser Hinsicht historisch getreu, indem er die Zugehörigkeit der Tschechen zu niedrigeren Gesellschaftsschichten bestätigt. Der einzige Deutsche, der im Text vorkommt und dessen Nationalität erst interpretatorisch erschlossen werden muss, gehört zum gehobenen Bürgertum. Seine Beziehung zu Jordán ist rein geschäftlich und er wird als Betrüger und damit ebenso negativ wie die tschechischen Figuren dargestellt. Die Nationalität spielt hier also hinsichtlich der moralischen Charakterisierung der Figuren keine Rolle. In der klaren Trennung der Welt eines armen tschechischen Studenten von den deutschen Großbürgern stimmt der Roman Mrštíks mit dem bekannten Bild Prags von Egon Erwin Kisch überein:

Mit der halben Million Tschechen der Stadt pflog der Deutsche keinen außergeschäftlichen Verkehr. Niemals zündete er sich mit einem Streichholz des Tschechischen Schulengründungsvereins eine Zigarre an, ebenso wenig ein Tscheche mit einem Streichholz aus einem Schächtelchen des Deutschen Schulvereins. Kein Deutscher erschien jemals im tschechischen Bürgerklub, kein Tscheche im Deutschen Casino. Selbst die Instrumentalkonzerte waren einsprachig, einsprachig die Schwimmanstalten, die Parks, die Spielplätze, die meis- 
ten Restaurants, Kaffeehäuser und Geschäfte. Korso der Tschechen war die Ferdinandstraße, Korso der Deutschen ,der Graben' [...]. Die deutsche und die tschechische Universität, die tschechische und die deutsche Technische Hochschule waren einander so fern, als wäre die eine am Nordpol, die andere am Südpol. (Kisch 1981: 81f.)

In Kischs Auffassung besteht Prag aus ethnisch isolierten Räumen, die ein nationales „Mosaik“ (Weinberg 2014: 20f.) bilden. Wie Manfred Weinberg anmerkt, ähnelt dieses Modell dem etwas anders strukturierten „dreifachen Ghetto“ (Eisner 1948: 66-82; zit. nach Weinberg 2014: 21) Pavel Eisners, das ebenfalls mithilfe von „klaren und harten Grenzen" (Weinberg 2014: 21) definiert ist, die in Wirklichkeit viel durchlässiger waren, als die beiden Modelle vermuten lassen. Im Vergleich zu Kisch und Eisner zeichnet allerdings Mrštík ein noch anderes Bild Prags, denn im Roman werden die Grenzen zwischen den beiden Ethnien nicht mal angesprochen, weil die deutschen Einwohner Prags gar nicht vorkommen. Bei den literarischen Schauplätzen Königliche Weinberge, Kleinseite, Wenzelsplatz, Graben und Neustadt handelt es sich dabei keineswegs um rein tschechische Gebiete Prags. Der Protagonist des Buches bewegt sich trotzdem durch einen Stadtraum, der (bis auf die erwähnte Ausnahme) scheinbar nur von Tschechen bewohnt wird und auf einen der Verhältnisse unkundigen Leser den Eindruck macht, dass es sich um eine rein tschechische Stadt handelt.

Der Zeitraum der Handlung lässt sich ungefähr auf Anfang der 1890er Jahre datieren, eine Zeit also, in der sich die politische Lage zwischen Tschechen und Deutschen in Böhmen zuspitzte und in der die tschechischen Studenten immer wieder antideutsche Bestrebungen zeigten. ${ }^{5}$ Das Bild einer tschechischen Gesellschaft, die auf irgendeine Weise politisch einheitlich auftreten und nationale Bestrebungen präsentieren würde, findet sich bei Mrštík jedoch nicht. Die Tschechen werden vom Erzähler, wie bereits angedeutet, im Allgemeinen als geld- und genusssüchtig dargestellt und für ihre gegenseitige Erniedrigungslust, Gehässigkeit und Hochmut kritisiert. Als einziger Ort des ,nationalen Zusammenhalts wird das bekannte Prager Gasthaus $U$ Fleku eingeführt. Jedoch verpufft auch hier die Utopie eines nationalen Zusammenhalts im Chaos sinnloser politischer Streitigkeiten.

Kdyby to byla jen pýcha, nadutost, peníze, hlupství! Urazí i ten, kdo nemá peněz, uštkne i ten, kdo dobře ví, že štípe a nemá k tomu důvodů; nadýmá se mrzák, pyšný je, i kdo v hadrech se narodil a zlodějstvím se dostal k zlatu, každý, kdo může, honosí se svou povýšeností nad druhým, hýří ve své slávě a podlosti. [...] Jenom u těch Fleků se to všechno sešlo jak sobě rovná zvěř - jinak každý svůj vzduch, svou vůni a smrad nosí s sebou, a běda tomu, kdo komu řekne bratře!

[Wäre es nur Hochmut, Überheblichkeit, Geld und Dummheit! Aber auch diejenigen, die kein Geld haben, verletzen andere; auch diejenigen, die gut davon wissen, dass sie andere, und zwar ohne Grund, kränken, tun es weiter; auch Krüppel plustern sich auf, auch jene sind hochmütig, die in Lumpen geboren wurden und durch Dieberei zu Gold kamen. Jeder, der es kann, prunkt mit seiner Überheblichkeit über die Anderen, schillert in seinem Ruhm und seiner Niederträchtigkeit. [...] Nur im U Fleků findet sich das alles zusammen wie Tiere, die einander gleich sind - sonst lebt jeder in seiner eigenen Luft, eigenem Geruch und Gestank und wehe dem, der einen anderen „Bruder“ nennt!] (Mrštík 1948: 259)

5 Ausführlich zu den deutsch-tschechischen studentischen Auseinandersetzungen siehe Wieser (1994: 6-26) und Veselá (2006: 107-109). 
Jordáns Begegnung mit der verfallenen Moral der Großstadt bestätigt logischerweise seine Outsider-Rolle. Im Unterschied zu den französischen desillusionistischen Texten, in denen nach der Desillusion entweder Resignation oder Anpassung an die sittlich verfallene Umgebung folgt oder die Hindernisse eines gesellschaftlichen Erfolgs durch das Aufgeben eigener moralischer Grundsätze (wie z.B. bei Stendhals Rot und Schwarz) zu überwinden sind, kann sich der Protagonist Mrštíks nicht in die verdorbene Gesellschaft integrieren. Das ergibt sich eigentlich schon aus dem Wesen seiner Illusionen, die v. a. humanistische und ethische Idealvorstellungen und keinen bloßen gesellschaftlichen Aufstieg anstreben. Die Hindernisse für seine Integration sind im Grunde unüberwindbar, denn die allgemeine Verdorbenheit der Gesellschaft kann von einem einzelnen nicht verändert werden.

Für die schlechten zwischenmenschlichen Verhältnisse werden in dem Text nicht die Klassenunterschiede, sondern der Verlust der Menschlichkeit verantwortlich gemacht. Die Einsicht des allgemeinen moralischen Verfalls in der Großstadt mündet bei Jordán in die Forderung nach einer Art radikalen Ethik, die „das Böse nicht dulden“ und „es auf jeden Schritt und Tritt verfolgen wird“, [„Netrpět zla, [...] pronásledovat ho v každém kroku] (Mrštík 1948: 298f.), bis es ausgerottet wird. Die materielle Gleichheit aller Menschen spielt dabei keine Rolle, die Botschaft des Textes ist also keineswegs eine sozialistische.

Prag als Ort des gesellschaftlichen Zerfalls wird, genauso wie in anderen Texten Mrštíks, in einen Kontrast zum mährischen Land gestellt, wo die patriotischen Illusionen weiter gelebt werden können. Durch das aufgezeigte Scheitern der humanistischen Ideale rechnet der Text eindeutig mit realistischen Grundsätzen ab, die in der großstädtischen Gesellschaft keinerlei Geltung mehr haben. Anders als in den französischen naturalistischen Romanen stellt allerdings die Figur Jordáns nicht den allgemeinen Typus des armen Studenten vom Lande in der Großstadt dar, sondern einen gescheiterten Versuch der Individualität (vgl. Pytlík 1989: 132), der Text funktioniert also eher wie eine Fallstudie. Das Individuelle der Figur wird durch die nuancierten Schilderungen der inneren Zustände Jordáns hervorgehoben, die sich konsequent auch in den Beschreibungen der äußeren Szenerie spiegeln. Die genauen Beschreibungen von Handlungsorten wechseln sich im Laufe der Handlung immer mehr mit Schilderungen symbolisch aufgeladener Träume und später mit Wiedergaben von schnell aufeinander folgenden und unzusammenhängenden Sinneseindrücken ab, die den delirösen Zustand des Protagonisten wiedergeben. Seine zum Schluss nur noch fragmentierte Wahrnehmung der Realität wird durch die graphische Zerstückelung des Textes durch verstärkten Einsatz von Gedankenstrichen hervorgehoben, welche für die naturalistische Schreibweise wie für die avantgardistische Moderne charakteristisch ist. Der Text steht somit literaturgeschichtlich gesehen bereits an der Kippe zum frühmodernen Naturalismus, obwohl seine Anfangspassagen sowie der auktoriale Erzähler noch der realistischen Tradition verpflichtet bleiben. Die Elemente der Fragmentierung der Realitätswahrnehmung, der Subjektivierung und Konzentrierung auf psychologische Vorgänge, die „vom vermeintlich Normalen“, d. h. realistischen abweichen, nähern sich bereits der „erzählerische[n] Routine“, die sich durch „erschwerte Textur des Textes“ (Baßler 2013: 15) und Konzentrierung auf „die Person, deren ,Natur“ dem Text die Regel gibt“ (Baßler 2016: 61), auszeichnet. 


\section{Antonín Sova: Výpravy chudých (1903)}

Explizit und kritisch bezieht sich der zehn Jahre später erschienene Roman Výpravy chudých (Die Unternehmungen der Armen) von Antonín Sova auf Santa Lucia. Sova, der eigentlich eher für seine symbolistische Lyrik bekannt ist, sehnte sich laut Arne Novák „immer von neuem nach den Bitternissen der krankhaften Gesellschaft“ und kehrte „immer wieder in die moderne, schwer atmende Großstadt zurück“ (Novák 1907: 363; zit. nach Wöll 2006: 498). Mit dieser Charakteristik sind der Ort und das Thema des Romans bereits umrissen. Wie bei Mrštík wird auch der Protagonist Sovas, Rudolf Martan, in einer kleinstädtischen Exposition mit der Begrenztheit der lokalen Verhältnisse und dem berechnenden Materialismus seines Vaters konfrontiert, was ihn zur Flucht in die böhmische Hauptstadt veranlasst. Hier hofft auch er seine Ideale einer „besseren und gerechteren Welt" (Schamschula 1996: 390) verwirklicht zu finden. Trotz der anfänglichen materiellen Not wird ihm von einem Philanthropen die soziale Integration in die Stadt ermöglicht und zwar unter expliziten Bezug auf den Roman Mrštíks:

Ztrácí se mnoho. Ale rozhodně není pravda, že studenti, kteří mají něco v hlavě, se najednou ztrácejí z obzoru, že píseň iluzí Santa Lucia zní pro ně tragicky. Aby se nenašlo včas vhodné a účinné pomocné ruky! Aby nebylo možno žíti z minimálního výdělku, když totiž skutečně $\mathrm{v}$ nás bouří něco, když to, co v nás je, dovedem uplatnit.]

[Manches geht verloren. Es ist aber sicher nicht wahr, dass Studenten, die was im Kopf haben, plötzlich so vom Horizont verschwinden, dass Santa Lucia, das Lied der Illusionen, tragisch für sie klingt. Die richtige helfende Hand findet sich immer! Und immer kann von dem kleinsten Erwerb irgendwie gelebt werden, wenn man nur einen stürmischen Geist hat, wenn man das, was man in sich hat, zur Geltung bringen kann.] (Sova 1960: 203)

Der Text streitet also die Behauptung der für zuziehende Studenten unzugänglichen Großstadt ab. Der Bezug auf den Protagonisten Mrštíks impliziert allerdings, dass Sova diesen nur als Typus des armen Studenten sieht. Das wird aber, wie oben gezeigt wurde, der Figur Jordáns in ihrer Komlexität nicht gerecht. Dass sich Sova noch 1903 auf den Roman Mrštíks bezieht, zeigt dessen nachhaltige Wirkung innerhalb der tschechischen Literaturszene.

Der autobiographisch angelegte Protagonist Sovas exemplifiziert den entsagenden Helden, der das Scheitern der Werte des Realismus zum Ausdruck bringt. Aus moralischer Überzeugung verzichtet er auf die notwendige finanzielle Unterstützung seines Vaters und später auch auf eine Liebesbeziehung. Seine Opfer zugunsten des Kampfes für eine bessere Gesellschaft haben jedoch keinerlei Wirkungen, da er allzu passiv bleibt und gegen das krisenhafte Zeitverständnis seiner Umgebung nicht aufkommen kann. Wie das obige Zitat andeutet, werden die materiellen Bedürfnisse Rudolfs im Verlauf der Handlung befriedigt. Im Unterschied zu dem einsam durch die Prager Straßen irrenden Protagonisten Mrštíks gelingt es ihm, Beziehungen zu anderen Menschen aufzubauen. Das praktische Leben kann jedoch seine sozialen Ideale der gesellschaftlichen Gerechtigkeit nicht befriedigen, denn diese erweisen sich auch in Prag als völlig utopisch. Im Text werden einerseits die elenden Bedingungen präsentiert, in denen die ärmsten sozialen 
Schichten leben, andererseits der absolute Zynismus, mit dem die junge Generation jedem Versuch um eine politische oder ideelle Auferweckung begegnet. So findet auch die flammende Rede eines Zeitkritikers kein Gehör:

Pro nás je však něma minulost. Stará kultura se promlčela se ztracenou svobodou a samostatností národa, [...]. To, kdož nám klečí na prsou, nepustí nás takto od země. [...] Nemáme géniů, srostlých s našimi dny, s našimi hodinami, s našimi činy př́itomnosti a s úkony budoucnosti. Máme od země odpoutané talenty, pohlížející do výší, do dálek, do hloubek... [...] ,Máme talenty a ne génie živných idejí, kteří by roztroušené síly národa sebrali a je ještě zmocnili novými aspiracemi...',A to je všechno?’ Zeptal se tentýž humorista kdesi vzadu. ,Kikirikíííí,' ozval se hrozně drze a komicky, takže celá místnost neubránila se bezcharakternímu, nakažlivému smíchu.

[Für uns verstummte die Vergangenheit. Mit der verlorenen Freiheit und der verlorenen Selbständigkeit der Nation verjährte die alte Kultur [...] Diejenigen, die auf unserer Brust knien, werden uns nicht freilassen, solange wir in einem solchen Zustand sind. [...] Wir haben keine Genies, die mit unserem Alltag, unseren Stunden, unseren gegenwärtigen und zukünftigen Taten verwachsen wären. Wir haben nur Talente, die dem Bodenständigen entrissen sind, in die Höhen, in die Ferne und in die Tiefe schauen... [...] Talente der Utopie und keine Genies, die die verstreuten Kräfte unserer Nation aufgreifen und durch neue Aspirationen potenzieren könnten... 'Und ist das alles?' fragte irgendwo hinten der Humorist. ,Kikirikííi rief er schrecklich frech und komisch, sodass sich der ganze Raum eines charakterlosen, ansteckenden Gelächters nicht erwehren konnte.] (Sova 1960: 304)

Die Deutschen bzw. die österreichische Monarchie werden zwar als Unterdrücker der tschechischen Nation erwähnt, der wirkliche Grund für den kulturellen Niedergang sind jedoch wie bei Mrštík die Tschechen selbst, die sich nur um ihre materiellen Bedürfnisse kümmern, zu feige sind, um sich gegen das Unrecht zu erheben und sich durch Geld kaufen lassen. Ihre geistige Elite erschöpft sich in bedeutungslosen Schwärmereien und Nihilismus, anstatt eine kulturelle Einheit zu bilden, die die Probleme der Zeit ins Visier nehmen würde. Die aktuelle junge Generation wird als ein Übergangsphänomen dargestellt. Sie wird entweder zur Genese einer neuen Nachkommenschaft führen, die sich von dem historischen, für die Moderne nicht mehr relevanten Nationalerbe der Tschechen befreit oder den Niedergang des tschechischen Geistes besiegelt.

Im Grunde wird hier das Bild des tschechischen Prag, wie schon zuvor bei Mrštík, in politisch wesentlich ausgeprägterer Form wiederholt. Im Sinne des Manifests Česká moderna (Tschechische Moderne, 1895), zu dessen Unterzeichnern sowohl Sova als auch Mrštík gehörten, kritisiert der Text die leeren politischen und ideellen Parolen und die konfuse geistige Situation der 1880er und 1890er Jahre. Das Manifest verurteilt außerdem jegliche „brutálnosti, které se pod národnostním heslem provádějí z německé strany tak, jak bychom je odsoudili, kdyby se prováděly z naší strany." [Brutalitäten, wie sie unter dem Stichwort der Nation auf deutscher Seite durchgeführt werden, so wie wir sie verurteilen würden, wenn sie von unserer Seite kämen.] (Krejčí/Machar/Šalda/Třebický u.a. 1895). Der Roman verzichtet dementsprechend auf konkrete Negativbilder der deutschsprachigen Bevölkerung Prags, es werden aber auch umgekehrt keine positiven Bilder des Deutschen präsentiert. Sie werden in beiden Romanen einfach nicht erwähnt. Es 
stellt sich daher die Frage, ob dieser Verzicht als impliziter Hinweis auf eine Ablehnung der Deutschen in Prag durch die beiden tschechischen Autoren gelesen werden kann.

Im Vergleich zu dem zehn Jahre früher erschienenen Roman Mrštíks konzentriert sich Sova mehr auf die Wiedergabe des gesellschaftshistorischen Kontextes (Studententreffen, Arbeiterbewegung, Armut aber auch Krise der Kunst), der häufig durch Gespräche und lange Monologe einzelner Figuren zum Ausdruck kommt.

Die Stadt wird nach der Ankunft Rudolfs als eine Frau charakterisiert, in die er „k smrti zamilovaný“ [bis auf den Tod verliebt] ist (Sova 1960: 171), die Inspiration durch Santa Lucia ist an dieser Stelle unverkennbar. Solch atmosphärische und emotionale Impressionen kommen allerdings im weiteren Verlauf des Textes nicht mehr vor, das Bild Prags beschränkt sich vielmehr auf das alltägliche Leben der Tschechen. Der Erzählstil ist größtenteils dem Realismus verbunden. Auffällig ist jedoch die häufige Verwendung der Auslassungspunkte, die lose aufeinander bezogene Gedanken miteinander verbinden sollen. Das Stilmittel wirkt allerdings in einigen Passagen unpassend oder redundant. Der innerhalb der tschechischen Literaturgeschichtsschreibung der ästhetischen Moderne zugerechnete Sova (vgl. Schamschula 1996: 389-391) bleibt in seiner Antwort auf Santa Lucia deutlich hinter der innovativen Kraft des Naturalisten Mrštíks zurück.

\section{Karl Hans Strobl: Die Vaclavbude (1902)}

Der für die deutsche Literatur gattungskonstituierende Studentenroman, der Strobls eigene Studentenzeit in Prag reflektiert, schildert die konfliktreichen Ereignisse um die Badeni-Krise 1897 in Prag aus der Sicht der deutschen Studenten. Die Handlung konzentriert sich auf den Zeitraum zwischen September und Dezember 1897, in dem sich nach dem Erlass der Badenischen Sprachverordnung und dem Rücktritt Badenis die politische Lage zwischen Tschechen und Deutschen zuspitzte und es zu Ausschreitungen und gegenseitigen Angriffen kam. Für Reiner Stach ist der Text „von deutschem Chauvinismus derart kontaminiert, dass glaubwürdiges Anschauungsmaterial von ihm kaum zu erwarten ist" (Stach 2014: 522). Das Bild der Tschechen ist im Text zwar tatsächlich überwiegend negativ und teilweise übertrieben gehalten, beinhaltet aber eben doch noch etliche Elemente, die eine schwarzweiße Darstellungsweise i. S. von guter, erhabener Deutscher und böser, tierischer Tscheche, deutlich untergraben, die beispielsweise in den eindeutig nationalistischen Grenzlandromanen vorherrschte. Die Vaclavbude ist außerdem - anders als Stach meint - als Zeugnis der beschriebenen Ereignisse von nicht unbedeutendem kulturellem und historischem Wert, wie Gabriela Veselá in ihrem Aufsatz verdeutlicht (vgl. Veselá 2006: 107-120). Die Rolle der Vaclavbude wird immer wieder (nur) als die des ersten deutschsprachigen Studentenromans gesehen, der frei „von der verlogenen Pseudoromantik à la Alt-Heidelberg“ (Wieser 1994: 41) ist. Der Text ist aber auch durch eine starke Desillusion hinsichtlich der deutschen nationalen Bestrebungen in Prag gekennzeichnet, was ihn mit Mrštíks Roman vergleichbar macht.

Die Protagonisten des Romans, deutsche Studenten und Mitglieder des Studentenvereins Franconia, sind mit der Absicht nach Prag gezogen, um am Kampf für die Pflege und Durchsetzung der deutschen Kultur gegen die Tschechen teilzunehmen und die Stadt 
Prag für sich zu erobern, die sowohl für die Deutschen als auch für die Tschechen nationale Symbolkraft besitzt. Nachdem die deutschen Studenten eine neue ,Bude für ihren Verein bei dem tschechischen Wirt Vaclav finden (was bereits der angeblich antitschechischen Haltung des Romans widerspricht), widmen sie sich den üblichen Tätigkeiten der Burschenschaften (Mensur, Gespräche über Couleurpolitik usw.). Mit der Eskalation der politischen Situation im Dezember 1897 rücken v. a. die Straßenkämpfe und Vorstöße der tschechischen Studentenschaft gegen die Deutschen in den Mittelpunkt des Geschehens, das schließlich in den Rückzug der Franconia-Mitglieder in ihre aktuell sichere Heimat mündet.

Im Unterschied zu Mrštíks zentralem Akteur Jordán sind die Protagonisten Strobls bereits zum Anfang des Textes zumindest in ihrem Verein integriert und leiden trotz ihrer ebenfalls sehr beschränkten finanziellen Verhältnisse bis zum Ende nicht unter lebensbedrohlicher Armut. Die schwierige Suche nach einem Obdach für ihren Kreis sowie die gegenseitige Rivalität zwischen den einzelnen Burschenschaften bringen jedoch auch in Strobls Text zum Ausdruck, wie problematisch die Eingliederung der aus böhmischen und mährischen Provinzen hinzuziehenden Studenten in die Prager Gesellschaft ist.

Die Studenten Binder und Horak, die sich im Laufe der Handlung als Hauptfiguren herauskristallisieren, glauben anfangs die für sie als ursprünglich deutsch (vgl. Strobl 1902: 105) empfundene Stadt Prag und die „deutsche Kulturarbeit“ (Strobl 1902: 166), d.h. ihre geistige Erhabenheit gegen die Tschechen verteidigen zu können, die die Hauptstadt für ihre Interessen gewinnen wollen. Die umkämpfte Metropole wird dabei mit dem Leben in der kleinstädtischen Heimat kontrastiert. Strobl besetzt die Heimatregion allerdings anders als Mrštík mit keinerlei nationalen Sehnsüchten und schreibt ihr die Funktion einer harmlosen Idylle zu, welche von „gutmütigen und dummen Spießbürger[n]" (Strobl 1902: 249) bewohnt wird. Der Umzug in die Hauptstadt dient als Beweis der Engagiertheit in nationalen Fragen. In den beiden Figuren werden im Text die zwei maßgeblichen Ansichten über die Durchsetzung deutscher Interesse präsentiert, die Illusion des gerechten Kampfes für die deutsche Nation scheitert, den unterschiedlichen Ansichten entsprechend, bei beiden Protagonisten auf unterschiedliche Weise. Der durch Krankheit geschwächte Horak resigniert bereits vorzeitig: „Es ist traurig, aber ich sage Euch, wir können Prag nicht halten. Wir stecken zu viel in diesen verlorenen Posten hinein. Geben wir ihn auf und schützen wir lieber sicherere und festere Grenzen mit aller Kraft.“ (Strobl 1902: 105)

Paradoxerweise wendet sich Horak, der väterlicherseits tschechische Wurzeln hat, später von seiner resignativen Haltung ab, wird (höchstwahrscheinlich gerade aufgrund seiner slawischen Abstammung) zu dem radikalsten unter seinen Kameraden und lehnt den Rückzug aus der Hauptstadt ab, was für ihn schließlich fatale Folgen hat: in Notwehr erschlägt er einen jungen Tschechen und erliegt später den Folgen der Verletzung, die ihn dieser zufügte (Strobl 1902: 255, 266).

Binder, in dem die Forschungsliteratur eine autobiographische Figur und somit die Ansichten des Autors selbst vertreten sieht (Maschke 2003: 174), widerspricht seiner Haltung. Er greift die in einer phantastischen Begegnung mit Tycho Brahe wiedergegebene Idee des „stärker Wollenden“ auf und wendet diese auf die deutsch-tschechischen Auseinandersetzungen an, in dem dementsprechend die Deutschen als die „stärkeren im Denken, [die] Tieferen im Gemüt“ schließlich siegen sollen. Der stärkere Wille und die 
kulturelle Erhabenheit müssen allerdings zumindest zeitweise den zahlenmäßig überlegenen Tschechen weichen. Obwohl das letzte Kapitel mit der Überschrift „Kein Ende“ suggerieren soll, dass dadurch der Kampf um Prag noch keineswegs beendet ist, impliziert der Rückzug aufs Land eine gewisse Resignation in Bezug auf die ursprünglichen Ideale des Kampfes für die eigene Kultur. Ähnlich wie bei Sova wird hier der Übergangscharakter der Zeit um 1900 unterstrichen, die erst durch den Sieg der deutschen Nation überwunden werden kann (Strobl 1902: 249).

Das Versagen der Protagonisten wird im Text zwar v. a. durch die Zusammenstöße mit den Tschechen begründet, ist allerdings auch mit der Stadt selbst verbunden. Prag wird wie bei Mrštík mehrfach als Figur personifiziert, die die slawische Feindlichkeit gegenüber den Deutschen verkörpert und sich gegen die Integration der Protagonisten wehrt:

In der Seele der großen Stadt war etwas wie ein hämisches Trotzen. Ganz tief, zu unterst lag es wie versteckt, aus gelben Augen tierisch blinzelnd. Binder empfand diese heimliche Bosheit unangenehm und drückend. Wenn er am Ufer der Moldau stand und hinüber sah, dann schienen ihm dichte, blaue Nebel über dem Berghang und Kleinseite am andern Ufer zu liegen ... dicht und schwer wie Tücher, mitten im hellsten Sonnenschein. Und am Abend glänzten die langen Fensterreihen des Hradschin wie Feuersignale. (Strobl 1902: 5)

\section{Später heißt es:}

Glaubt mir, diese Stadt ist die Opfer nicht wert, die sie von uns fordert. Wie eine böse Krankheit saugt sie an unserer Kraft. Ein Feind, der würgt und tötet, ohne daß man ihn fassen kann. Er hat starke, giftige Waffen: Den Typhus und die Weiber. (Strobl 1902: 106)

Die Bilder Prags, denen wie in Santa Lucia eine impressionistische Flüchtigkeit eigen ist, nehmen in der Vaclavbude eindeutig weniger Platz ein als die seitenlangen Beschreibungen bei Mrštík, ihre Rolle ist jedoch vergleichbar - sie symbolisieren die Unzugänglichkeit der Stadt für die Deutschen. Eine deutliche Parallele ist auch die Konnotation Prags mit dem Krankhaften und Weiblichen. Horak z.B. erkrankt nach einer erotischen Affäre mit der tschechischen Kellnerin Marie an einer Geschlechtskrankheit und stirbt später wie Jordán an „Lungenblutung“ (Strobl 1902: 266). Wie Santa Lucia spielt außerdem auch die Vaclavbude in dem Milieu zweifelhafter Lokale und ist mit vielen Beschreibungen realer Prager Orte ausgestattet, wobei v. a. die detaillierten Bilder der bereits zum Teil abgerissenen Judenstadt, in der sich die titelgebende Vaclavbude befindet, die Atmosphäre der Geschichte prägen. Während die Prag-Panoramen bei Mrštík Jordáns Verträumtheit untermalen sollen, bewirken die dunklen Gassen und Räumlichkeiten der alten Judenstadt bei Strobl eher eine düstere Atmosphäre, die, so Wieser, „in unerhörter Plastizität“ (Wieser 1994: 49) und fotografisch anmutenden Aufnahmen vermittelt wird.

Das allgemein negative Bild der Tschechen, das Strobl vorgeworfen wird, wird im Text an mehreren Stellen relativiert. So werden beispielsweise die tschechischen Stammgäste der Vaclavbude als „brave Handwerker und Bürger“ (Strobl 1902: 36) charakterisiert, die „Frankonen“ wohnen sogar friedlich einer ihrer Feiern bei. Die Vaclavbude fungiert im Text als ein Ort, an dem ein gemeinsames deutsch-tschechisches Dasein 
möglich ist. An anderen Orten verhalten sich die Tschechen den Deutschen gegenüber freilich feindsinnig, und mit Beginn der Straßenkämpfe formieren sie sich letztlich zu einer völlig homogen beschriebenen Masse, die das Niedere, Tierische und kulturell Unterlegene des Slawentums repräsentieren soll und aggressiv gegen alles Deutsche vorgeht:

Es war ein unheimlich prächtiger Eindruck. Diese ganze tobende Volksmasse wälzte sich auf sie [die deutschen Studenten; AP] zu. Es war keine Masse von einzelnen mehr, es war selbst ein Thier mit hunderten von Köpfen und einem Willen; wie ein ungeheuer schwarzer Schlangenleib kroch es am Boden... (Strobl 1902: 156)

Im Vergleich mit Santa Lucia, wo Mrštík die moralische sowie politische Zerbröckelung der Prager Tschechen anprangert, liefert also Strobl ein völlig gegensätzliches Bild von Tschechen, die in ihren nationalen Interessen einheitlich auftreten und politisch keineswegs gleichgültig sind. Dieses Bild ergibt sich freilich aus der angespannten Situation der Badeni-Stürme, obwohl eine objektive Darstellungsweise der Ereignisse höchst problematisch ist (Stach 2014: 522). Das einheitliche, antideutsche Tschechenbild ist für den Text natürlich auch deswegen notwendig, weil es dessen Funktion mitkonstituiert, das eigene Nationalbewusstsein zu stärken. Im breiteren Sinne lässt sich daher die Vaclavbude, so Karsten Rinas (2017) in seiner Studie zum Grenzlandroman, in den Kontext der Grenzlandliteratur einsetzen, in der die Deutschen als die durch die demographisch sowie politisch immer stärkere Gruppe der Tschechen bedrohte Nation dargestellt werden und deren Texte „zur Stärkung und Erhaltung der eigenen Nationalkultur“ (Schamschula 1996: 342) dienen sollten. Es ist allerdings interessant, dass der national gestimmte Roman die gegenseitigen Kontakte und Koexistenz der Deutschen und Tschechen anspricht, während die oben besprochenen tschechischen Texte das Thema des Zusammenlebens verschweigen. Trotz der Grenzland-Thematik, die früher üblicherweise als literarisch minderwertig abgetan (vgl. Rinas 2017: 314) und mit der Antimoderne verbunden wurde, weist die Vaclavbude in seinen genauen Beschreibungen deutliche Züge des Naturalismus auf, unter dessen Einfluss Strobl in seiner frühen Schaffensphase stand (Peštová 2013: 10f.). Dem entspricht auch der episodenhafte Charakter des Textes, der sich von der linearen Erzählweise des Realismus klar unterscheidet und in Ansätzen an die sequentielle Strukturierung von Filmszenen erinnert.

Der auf diesem begrenzten Raum freilich nur skizzenhafte Vergleich der drei Romane ließe sich um weitere Werke erweitern. Gabriela Veselá (2006: 107-120) verglich die Vaclavbude mit dem tschechischen Roman Prosinec (Dezember, 1906) von Viktor Dyk (1877-1931), der sich mit den Badeni-Stürmen aus der Perspektive tschechischer Studenten auseinandersetzt und durch antideutsche Tendenzen geprägt ist. Auch hier wird jedoch das Scheitern des nationalen Kampfes durch den schwachen Charakter der Tschechen begründet, deren Fähigkeiten nicht genügen, um ihre Befreiung von der deutschen Dominanz zu erkämpfen. Interessante Parallelen und Kontraste ließen sich auch zu dem Wiener Studentenroman Am Wege Sterben (1900) des Deutschmährers Jakob Julius David (1859-1906) ziehen, der ganz im Sinne des Zolaschen Experiments die klischeehaften tschechischen, deutschen und jüdischen Nationalstereotype in Studentenfiguren 
gegeneinander ausspielt und ebenfalls die schwierige Eingliederung in die Großstadt thematisiert. $^{6}$

Aber bereits die durchgeführten Vergleiche und Analysen berechtigen zu einigen Schlussfolgerungen. Der Studentenroman, der sich als Unterhaltungsgenre um 1900 in Deutschland großer Popularität erfreute, findet auch in den Böhmischen Ländern wichtige Vertreter, welche allerdings über den bloßen Unterhaltungszweck und die reine Schilderung von „Freuden und Wirren des Studentenlebens“ (Weierhausen 2004: 61) und von „Mensuren, Kommerse[n], [...] kleine[n], nichtssagende[n] Liebesabenteuer[n]“ usw. (Raché 1904: 834; zit. nach Weierhausen 2004: 61) hinausgehen. Strobl geht zwar mit dem für ihn charakteristischen Humor in der Vaclavbude auf diese typischen Elemente detailliert ein, der Text will jedoch den zugespitzten Nationalkonflikt aufzeigen. Die tschechischen Studentenromane beziehen sich hingegen auf französische Romane, die gesellschaftliche Aufsteiger präsentieren, und konzentrieren sich daher gezielter auf die existentiellen Probleme der Protagonisten. Da die tschechischen Studentenvereine im Vergleich zu den deutschen Korps vor 1900 deutlich unterentwickelt waren (Dowe 2009: 175-185), spielt das Studentenmilieu in den tschechischen Texten eine deutlich geringere Rolle. Trotz aller Unterschiede kann man feststellen, dass die im politisch umkämpften Prag spielenden Studentenromane, und zwar sowohl der von Strobl als auch die tschechischen Texte, stark im Interesse einer nationalen Erweckung funktionalisiert wurden. Beide Seiten benutzen dazu unterschiedliche Strategien. Während die Prager Tschechen bei Strobl und anderen deutschnationalen Autoren um die Jahrhundertwende als klar nationalistisch und antideutsch dargestellt werden, gibt es zur gleichen Zeit tschechische Eigenbilder, die eine politisch desinteressierte und ideell zersplitterte Prager Gesellschaft zum Vorschein bringen. Während die Deutschen Studenten in der Vaclavbude an den Tschechen scheitern, sind sich in den tschechischen Texten die Tschechen selbst der größte Feind. Während in dem Roman Strobls also die Tschechen als Bedrohung instrumentalisiert werden, um die Deutschen zum nationalen Entscheidungskampf zu motivieren, nutzen die tschechischen Autoren das kritische Bild der eigenen Nation und Kultur, um diese zu einem höheren Nationalbewusstsein zu mobilisieren.

Bemerkenswert ist das fast völlige Fehlen deutscher Figuren in den tschechischen Texten, was bei der Lektüre den Eindruck einer homogenen tschechischen Gesellschaft erweckt, der mit der historischen Wirklichkeit keineswegs übereinstimmt. Damit hängt auch ein Phänomen zusammen, das sich in der Forschung (nicht nur) zu den genannten Texten bemerkbar macht - während man sich bei der Untersuchung deutschböhmischer sowie deutschmährischer Texte der beiden bzw. der drei hier vorhandenen Ethnika immer bewusst ist und ihr Bild bzw. ihr Fehlen bei der Textinterpretation berücksichtigt, geht die tschechische Literaturgeschichtsschreibung häufig nur auf das im Text explizit Genannte ein und lässt den historischen Kontext des deutsch-tschechischen Zusammen-

6 Davids Texte bieten sich geradezu zu einem Vergleich mit der tschechischen Literatur an, weil sie sehr häufig tschechische Figuren präsentieren. Der Roman Am Wege sterben ist umso interessanter, als er ein deutlich negatives und mit üblichen nationalen Klischees ausgestattetes Tschechenbild vermittelt. Dieses kontrastiert mit den tschechischen Figuren in Davids mährischen Erzählungen, die neutral oder häufig gar positiv geschildert werden und kaum national bedingte Eigenschaften aufweisen. Vgl. zu diesem Thema Budňák (2010: 129-135). 
lebens völlig außer Acht. Das auf diese Weise überlieferte, vereinfachende Bild trägt somit dazu bei, dass die gemeinsame deutsch-tschechische Geschichte der Böhmischen Länder noch mehr in Vergessenheit gerät. Gerade eine solche Kontextualisierung von auf diese Weise bisher nicht untersuchten Texten sowie der anschließende Vergleich mit deutschen Werken könnte dabei kleinteilige Wandlungen der nationalen Eigen- und Fremdbilder und des Selbstverständnisses der beiden Nationen aufdecken und damit zum Erkunden der gemeinsamen Kulturgeschichte beitragen.

\section{LITERATUR}

Baßler, Moritz (2013): Zeichen auf der Kippe. Aporien des Spätrealismus und Routines der frühen Moderne. In: ders. (Hg.): Entsagung und Routines. Aporien des Spätrealismus und Verfahren der frühen Moderne. Berlin: De Gruyter.

Baßler, Moritz (2016): Routines, Fallstudien, Rauschen: Verfahren des Naturalismus. In: Innerhofer, Roland / Strigl, Daniela (Hgg.): Sonderweg in Schwarzgelb? Auf der Suche nach einem österreichischen Naturalismus in der Literatur. Innsbruck: Studienverlag.

Becker, Sabina (2003): Bürgerlicher Realismus. Tübingen/Basel: Francke.

Budňák, Jan (2010): Das Bild des Tschechen in der deutschböhmischen und deutschmährischen Literatur. Olomouc: Univerzita Palackého.

Dowe, Christopher (2009): Českí buršáci?!? : Národné farby v študentských konfliktoch v Prahe okolo roku 1900. In: Kováč, Dušan / Marek, Michaela / Pešek, Jiří (Hgg.): Kultura jako nositel a oponent politických záměrů: Německo-české a německo-slovenské kulturní styky od poloviny 19. století do současnosti, Ústí nad Labem: Albis international, 175-185.

Hobland, Wolfgang (1991): Der Naturalismus in der tschechischen Literatur. München: Verlag Otto Sagner (Marburger Abhandlungen zur Geschichte und Kultur Osteuropas 29), 50-63.

Hodrová, Daniela (1989): Román ztracených iluzí. In: dies.: Hledání románu. Kapitoly z historie a typologie žánru. Praha: Československý spisovatel, 127-138.

Kisch, Egon Erwin (1981): Deutsche und Tschechen. In: ders.: Markplatz der Sensationen. Berlin: Aufbau Verlag, 72-80.

Krejčí, František Václav / Machar, Josef Svatopluk / Šalda, František Xaver / Třebický, Jan et. al. (1895): Česká moderna. In: Rozhledy 5, č. 1, 1-4; online unter: http://www.ceskaliteratura.cz/dok/mmoderny.htm [Stand: 28.09.2016].

Maschke, Marta (2003): Der deutsch-tschechische Nationalitätenkonflikt in Böhmen und Mähren im Spiegel der Romane von Karl Hans Strobl. Berlin: dissertation.de - Verlag im Internet.

Mrštík, Vilém (1948): Santa Lucia. Praha: Ladislav Kuncír.

Novák, Arne (1907): Die čechische Litteratur der Gegenwart. Leipzig: C. F: Amelangs Verlag.

Pestová, Alžběta (2013): Mittelachsenlyrik. Die Rezeption von Arno Holz in Böhmen und Mähren. In: Germanoslavica. Zeitschrift für germano-slawische Studien 26, H. 1-2, Prag, 84-102.

Pytlík, Radko (1989): Vilém Mrštík. Osud talentu v Čechách. Praha: Melantrich.

Raché, Paul (1904): Jena oder Heidelberg? In: Das literarische Echo. Halbmonatsschrift für Literaturfreunde 6, H. 9, 832-838.

Rinas, Karsten (2017): Grenzland. In: Becher, Peter / Höhne, Steffen / Krappmann, Jörg / Weinberg, Manfred (Hgg.): Handbuch der Literatur zur deutschen Literatur Prags der Böhmischen Länder. Stuttgart: Metzler, 307-318.

Schamschula, Walter (1996): Geschichte der tschechischen Literatur. Von der Romantik bis zum Ersten Weltkrieg. Köln: Böhlau.

Sova, Antonín (1960): Výpravy chudých. Z kroniky osamělého studenta. Praha: Československý spisovatel.

Stach, Reiner (2014): Kafka. Die Frühen Jahre. Frankfurt am Main: S. Fischer Verlag.

Strobl, Karl Hans (1902): Die Vaclavbude. Ein Prager Studentenroman. Leipzig: Hermann Seemann Nachfolger. 
Veselá, Gabriela (2006): Studentenromane in der deutsch-böhmischen und tschechischen Literatur. In: Germanoslavica. Zeitschrift für germano-slawische Studien 17, H. 1-2. Prag, 107-120.

Weierhausen, Romana (2004): Wissenschaft und Weiblichkeit. Die Studentin in der Literatur der Jahrhundertwende. Göttingen: Wallstein.

Weinberg, Manfred (2014): Die Grenzen der Interkulturalität. Interkulturelle Raumkonzepte am Beispiel der Prager deutschen Literatur. In: Fiala-Fürst, Ingeborg (Hg.): Prager deutsche, deutschböhmische und deutschmährische Literatur. Eine Neubestimmung. Olomouc: Univerzita Palackého, 7-32.

Wieser, Walter G. (1994): Der Prager deutsche Studentenroman in den ersten vier Jahrzehnten des 20. Jahrhunderts. Wien: W. G. Wieser.

Wöll, Alexander (2006): Jakub Deml. Leben und Werk (1878-1961). Köln: Böhlau.

\author{
Mgr. Alžběta Peštová \\ Lehrstuhl für Germanistik, Philosophische Fakultät, Palacký-Universität Olomouc \\ AlzbetaPestova@seznam.cz
}

